\title{
A LEMON a Day Keeps Fatigue Away - The ABCDE of Fatigue
}

\author{
Sanjay Kalra ${ }^{1}$ and Rakesh Sahay ${ }^{2}$ \\ 1. Department of Endocrinology, Bharti Hospital, Karnal, India; 2. Department of Endocrinology, Osmania Medical College, Hyderabad, India
}

DOl: https://doi.org/10.17925/EE.2018.14.1.15

$\mathrm{F}$ atigue is a common symptom in clinical medicine. The complex and multifaceted etiopathogenesis of fatigue is a challenge for the differential diagnosis and management of fatigue. This brief communication shares two simple mnemonics - LEMON and ABCDE which help in the evaluation of fatigue. These frameworks are as relevant to endocrinology and diabetes as to general practice. The mnemonic LEMON stands for lifestyle, endocrine, medical/metabolic, observer (physician) and nutrition-related factors which may cause fatigue; $A B C D E$ lists the aetiology of fatigue in three columns related to physiological/nutritional, psychosocial and biomedical causes (each column includes one cause and how this relates to the ABCDE rubric).

\section{Keywords}

Diabetes fatigue syndrome, endocrine fatigue syndrome, energy, salutogenesis, type 1 diabetes, type 2 diabetes

Disclosure: Sanjay Kalra and Rakesh Sahay have nothing to declare in relation to this article.

Review Process: This article is a short opinion piece and has not been submitted to external peer reviewers but was reviewed for accuracy by the editorial board before publication.

Authorship: All named authors meet the criteria of the International Committee of Medical Journal Editors for authorship for this manuscript, take responsibility for the integrity of the work as a whole and have given final approval for the version to be published.

Open Access: This article is published under the Creative Commons Attribution Noncommercial License, which permits any non-commercial use, distribution, adaptation and reproduction provided the original author(s) and source are given appropriate credit. (C) The Authors 2018.

Received: 2 March 2018

Published Online: 18 April 2018

Citation: European Endocrinology. 2018;14(1):15-16

Corresponding Author: Sanjay Kalra, Bharti Hospital, Karnal 132001, India. E: bridekn|@gmail.com

Support: No funding was received in

the publication of this article.
Fatigue is a frequently encountered symptom in clinical practice. ${ }^{2}$ This is especially so in endocrine clinics, which have a higher proportion of persons living with chronic disease. While debate continues regarding the exact definition and measurement of fatigue, ${ }^{2}$ it is not difficult to recognise fatigue in the medical setting. Defined as a feeling of tiredness or exhaustion or a need to rest because of lack of energy or strength, fatigue can present as physical, mental or sexual weakness. ${ }^{3}$ Patients may complain of difficulty in carrying out normal activities of daily living, inability to work energetically or a feeling of tiredness even upon waking up.

\section{Aetiology of fatigue}

The wide range of symptomatology of fatigue is matched by an equally long list of causes of fatigue. The overall clinical picture is diverse enough to be termed as a syndrome of chronic presentation (chronic fatigue syndrome), ${ }^{4}$ which may be specific to medical conditions (diabetes fatigue syndrome). ${ }^{5}$

Because of this heterogeneity, it sometimes becomes challenging to evaluate various differential diagnoses of fatigue. This implies that it is not always possible to address the patient's complaints and resolve fatigue.

\section{Differential diagnosis}

Taking a cue from the adage 'an apple a day keep the doctor away', we posit a new adage: 'a LEMON a day keeps fatigue away'. LEMON is a simple mnemonic which lists various aetiologies of fatigue in five categories (Table 1). Fatigue can be due to lifestyle, endocrinopathy, metabolic disturbance, medical diseases, observer (physician) error, or nutritional deficiency. The various causes are listed and classified in Table 1. One must note that many cases of fatigue are due to lifestyle or nutritional factors. While medical and endocrine diseases, as well as iatrogenic causes, must be ruled out, one must focus on lifestyle and nutrition optimisation as well. The table includes various screening and diagnostic tools which may help identify the aetiology of fatigue. It must be noted that these tools are not limited to biochemical investigations or endocrine assays; they include clinical features and patient-reported instruments such as the Glucocoper (a tool to assess for coping skills) and the Diabetes Distress Scale (a scale to measure diabetes distress). ${ }^{6.7}$

The ABCDE mnemonic divides causative factors of fatigue into physiological/nutritional, psychosocial and biomedical, and uses simple nomenclature to list these causes in alphabetical order (Table 2).

\section{Discussion}

With LEMON, we have purposely used a salutogenic or health-promoting title rather than a pathogenesis-based heading to list the aetiologies of fatigue. This should help facilitate a positive approach amongst health care professionals. The brief nature of this table belies the comprehensive coverage of pathophysiology and clinical features that it succeeds in achieving. The self-explanatory columns facilitate its use as an aid to clinical decision making and management. 
Table 1: A LEMON a day keeps fatigue away

\begin{tabular}{|c|c|c|c|}
\hline \multicolumn{2}{|l|}{ Class } & Aetiology & Screening/Diagnosis \\
\hline \multirow{3}{*}{\multicolumn{2}{|c|}{ Lifestyle }} & Physical activity/exercise, lack of & History taking \\
\hline & & Stress & GlucoCoper/Diabetes Distress Scale \\
\hline & & Sleep hygiene, impaired & Sleep questionnaires \\
\hline \multirow[t]{6}{*}{ Endocrine } & \multirow[t]{3}{*}{ Common } & Thyroid disorders & TSH \\
\hline & & Diabetes & HbA1C, continuous glucose monitoring \\
\hline & & Hypogonadism & Testosterone oestrogen \\
\hline & \multirow[t]{3}{*}{ Relatively uncommon } & Hypopituitarism & LH, FSH, testosterone/oestrogen; TSH, thyroxine \\
\hline & & Adrenal disorders & Serum cortisol, ACTH stimulation test \\
\hline & & Parathyroid disorders & Serum PTH, calcium, alkaline phorphatase \\
\hline \multirow{3}{*}{\multicolumn{2}{|c|}{ Metabolic }} & Dyselectrolytemia & Clinical context, serum electrolytes \\
\hline & & Fluid metabolism disorders & Clinical context/dehydration \\
\hline & & Vitamin D deficiency & $\begin{array}{l}25 \text { hydroxy vitamin D } \\
<30 \text { ng/ml (insufficiency) or } \\
<20 \text { ng/ml (deficiency) }\end{array}$ \\
\hline \multirow{3}{*}{\multicolumn{2}{|c|}{ Medical }} & Hepatorenal impairment & Renal/hepatic function tests \\
\hline & & Rheumatologic disease & Clinical features, C-reactive protein, ANA, rheumatoid factor \\
\hline & & $\begin{array}{l}\text { Gastrointestinal dysfunction } \\
\text { - motility disorders } \\
\text { - malabsorption }\end{array}$ & $\begin{array}{l}\text { Clinical features, faecal fats, faecal elastase, antigliadin and } \\
\text { antiendomysial antibodies }\end{array}$ \\
\hline \multirow{3}{*}{\multicolumn{2}{|c|}{ Observer (Physician) }} & Drug-induced fatigue & Drug history \\
\hline & & Inappropriate treatment & Drug history \\
\hline & & Complementary and alternative medicine & Drug history \\
\hline \multirow{3}{*}{\multicolumn{2}{|c|}{ Nutritional }} & Macronutrient deficiency & Dietary review \\
\hline & & Micronutrient deficiency & Dietary review \\
\hline & & Meal distribution/pattern & Diet recall \\
\hline
\end{tabular}

ACTH = adrenocorticotrophic hormone; ANA = anti-nuclear antibodies; FSH = follicle stimulating hormone; HbA1C=glycated haemoglobin; $L \mathrm{H}=1$ luteinising hormone; PTH = parathormone; TSH = thyroid stimulating hormone.

Table 2: The ABCDE of diabetes fatigue syndromes

\begin{tabular}{|c|c|c|c|}
\hline & Nutritional/Physiologic & Psychosocial & Biomedical \\
\hline A & Ageing & $\begin{array}{l}\text { Apnoea (obstructive sleep apnoea): poor sleep } \\
\text { hygiene, sleep deprivation }\end{array}$ & Anaemia: iron deficiency, renal impairment, drug induced \\
\hline B & $\begin{array}{l}\text { Vitamin B1, B6, B12 } \\
\text { deficiency }\end{array}$ & Behavioural issues: diabetes distress, depression & Bulimia/anorexia nervosa \\
\hline C & $\begin{array}{l}\text { Calorie restriction/ } \\
\text { inadequacy }\end{array}$ & Conditioning, poor physical & Comorbid conditions: renal, hepatic, gastrointestinal disease \\
\hline D & Vitamin D deficiency & $\begin{array}{l}\text { Drug-induced: glucose-lowering, non-metabolic } \\
\text { drugs; complementary and alternative medicine/ } \\
\text { substance abuse }\end{array}$ & $\begin{array}{l}\text { Diabetes complications: nephropathy, heart failure, } \\
\text { infections/infestations }\end{array}$ \\
\hline E & Dyselectrolytemia & Exercise, lack of & Endocrine dysfunction: thyroid, adrenal, gonad \\
\hline
\end{tabular}

In the ABCDE of fatigue, we utilise a framework which lends itself to easy memorisation. This allows it to be used as a teaching tool and serves as a basis for further understanding of the concept of fatigue in diabetes, as well as in general medicine. $\square$
1. Fritschi C, Quinn L. Fatigue in patients with diabetes: a review. J Psychosom Res. 2010;69:33-41.

2. Phillips RO. A review of definitions of fatigue - And a step towards a whole definition. Transp Res Part F Traffic Psycho Behav. 2015;29:48-56.

3. Thesaurus.com. Fatigue. 2018. Available at: http://www. dictionary.com/browse/fatigue?s=t (accessed 28 February 2018). . Evengård B, Klimas N. Chronic fatigue syndrome: probable pathogenesis and possible treatments. Drugs. 2002;62:2433-46. 5. Goedendorp MM, Tack CJ, Steggink E, et al. Chronic fatigue in type 1 diabetes: highly prevalent but not explained by hyperglycemia or glucose variability. Diabetes Care.
2014;37:73-80.

6. Kalra S, Verma K, Singh YB. Management of diabetes distress. J Pak Med Assoc. 2017;67:1625-7.

7. Behavioral Diabetes Institute. Scales and measures. 2017. Available at: http://behavioraldiabetes.org/scales-and-measures/ \#1448434304099-9078f27c-4106 (accessed 29 March 2018). 